\title{
Variability in laboratory reporting practices for regions of homozygosity indicating parental relatedness as identified by SNP microarray testing
}

\author{
Lauren Grote, BS ${ }^{1,2}$, Melanie Myers, PhD, MS ${ }^{1,2}$, Anne Lovell, MSN, CNP ${ }^{1,2}$, Howard Saal, MD ${ }^{1,2}$ \\ and Kristen Lipscomb Sund, PhD, MS ${ }^{1,2}$
}

Purpose: Single-nucleotide polymorphism (SNP) microarrays are capable of detecting regions of homozygosity $(\mathrm{ROH})$ that can suggest parental consanguinity or incest. This study was designed to describe the variable reporting practices of clinical laboratories in the United States regarding ROH found on SNP microarray tests, to discuss the follow-up practices of laboratory personnel when findings of $\mathrm{ROH}$ indicate consanguinity or incest, and to highlight the legal and ethical dilemmas faced by workers who have discovered these incidental findings.

Methods: A 20-question survey was administered to microarray experts at 18 laboratories offering clinical SNP microarray tests. The results are presented using descriptive statistics.

\section{INTRODUCTION}

Single-nucleotide polymorphism (SNP) microarrays are frequently performed as part of the diagnostic work-up for individuals with developmental disabilities and/or congenital anomalies. These microarrays identify duplications and deletions as well as regions of homozygosity $(\mathrm{ROH})$ throughout the genome. Constitutional $\mathrm{ROH}$ are consistent with uniparental isodisomy (UPD), ancestral relatedness, or consanguinity. ${ }^{1-4} \mathrm{~A}$ single $\mathrm{ROH}$ or multiple $\mathrm{ROH}$ on the same chromosome may represent UPD, which can be confirmed by means of methylation analysis, microsatellite analysis of parental and patient samples, or trio microarray SNP genotype analysis. ${ }^{5-7}$ The inheritance of small identical chromosomal segments can occur without immediate parental relatedness. These moderate-sized $\mathrm{ROH}$ $(>4 \mathrm{MB})$ have been found to occur frequently across all populations, and are termed ancestral $\mathrm{ROH}^{8,9}$ In contrast, long, uninterrupted $\mathrm{ROH}$ on multiple chromosomes are present in individuals who are the product of a consanguineous relationship. ${ }^{7,8}$

In clinical genetics, consanguinity is defined as the union of individuals related as second cousins or closer. ${ }^{10}$ Worldwide, couples who are second cousins or closer and their children form $10.4 \%$ of the population. ${ }^{10}$ Rates of consanguinity are influenced by ethnicity, religion and culture. Consanguinity is more common in the Middle East, North Africa, and West Asia,
Results: There was variability in laboratory SNP microarray reporting practices with respect to information and interpretation of $\mathrm{ROH}$ findings. All the laboratories agreed that they have a duty to inform the ordering physician about results suggesting consanguinity or incest, but the follow-through practices varied among laboratories.

Conclusions: This study discovered variability in reporting practices and follow-up procedures for microarray results that suggest parental consanguinity or incest. Our findings highlight the need for laboratory guidelines to standardize reporting practices for SNP microarray and other tests that are capable of detecting $\mathrm{ROH}$.

Genet Med 2012:14(12):971-976

Key Words: consanguinity; heterozygosity; incest; microarray; regions of homozygosity

where it is thought to comprise $20->50 \%$ of all marriages. ${ }^{10-12}$ In the United States, consanguinity is significantly less common, and is estimated to occur in $<5 \%$ of marriages, with certain parts of the United States having higher rates than others. ${ }^{11-13}$ The difference is believed to be due to Western attitudes toward consanguinity, and the laws discouraging relationships between individuals related as first cousins (third-degree relatives) or closer. In the United States, marriages between first cousins or closer are illegal and constitute a criminal offense in 31 of the 50 states. ${ }^{10,14}$ In all 50 states, incest is classified as sexual relations between first-degree relatives, such as between a parent and child or between two biological siblings. In some states, incest also includes sexual relations between second-degree relatives, for example a relationship between half-siblings, an aunt and a nephew, an uncle and a niece, or a grandparent and a grandchild. ${ }^{14,15}$ Offspring of both consanguineous and incestuous unions are at increased risk for autosomal recessive disorders. Empirical studies show that the progeny of first-cousin relationships are at an increased risk for stillbirths and infant mortality; in addition, the risk for birth defects is $2-3 \%$ greater than for the generation population. ${ }^{11,12,16}$

Identification of homozygosity can be useful for clinical diagnoses. $\mathrm{ROH}$ guide clinicians toward methylation analysis for UPD syndromes and candidate gene sequencing for identification of 
recessively inherited disease-causing mutations. ${ }^{6,7}$ Information about $\mathrm{ROH}$ may also be useful for the discovery of new syndromes. ${ }^{16,17}$ Although the detection of $\mathrm{ROH}$ may be clinically useful for diagnosis, it also has the potential to raise significant legal and ethical concerns. Discovery of a parental consanguineous or incestuous relationship (a blood relationship between the parents of the proband) by SNP microarray may come as a surprise to the laboratory, the ordering physician, and even to the family. There are currently no standards for reporting the results of clinical SNP microarrays that show multiple ROH, suggestive of consanguinity or incest. In the absence of standards, it is not known what, if any, information laboratories are including in their microarray reports about $\mathrm{ROH}$ and the implications of $\mathrm{ROH}$. It is also unclear whether results suggesting consanguinity or incest are being communicated to the ordering physician or to the family of the patient, where these are not directly stated on the report. In this study, microarray experts at laboratories that perform clinical SNP microarrays were surveyed to determine how they report the detection of ROH. This description of laboratory reporting practices will be useful in the development of standards for responsible reporting of $\mathrm{ROH}$.

\section{Participants and procedures}

\section{MATERIALS AND METHODS}

Clinical laboratories throughout the United States that offer SNP microarray testing of peripheral blood samples met the inclusion criteria for this study. Laboratories that did not offer SNP microarrays or that offered SNP microarrays solely for oncology analysis were excluded. Eligible laboratories were identified by attendance of personnel at cytogenetics conferences, and snowball sampling or identification of potential participants through other participants. Laboratory websites were reviewed to confirm that SNP microarray was offered as a diagnostic test. In addition, laboratories were contacted before being invited to participate in the survey, in order to verify that they did offer SNP microarray testing on a clinical basis. Once the preliminary verification was complete, microarray experts at each of the laboratories were identified to complete the survey. The experts were identified by contacting the main telephone number of the laboratory and asking to speak to a person involved in creating/editing SNP microarray reports. All respondents confirmed their status as microarray experts by responding "yes" to the question, "Are you familiar with your laboratory's process of finding and reporting $\mathrm{ROH}$ on a SNP microarray?" This article includes data from the laboratories' perspective. A forthcoming paper will address genetic counselors and geneticists' perspectives on pre- and post-counseling relating to the results of SNP microarray testing, and the associated legal and ethical dilemmas the providers of the information may face. This study was approved by Cincinnati Children's Hospital Medical Center and The University of Cincinnati institutional review boards (Study no. 2011-1248).

\section{Development of the survey}

A 20-item survey was developed to assess the variability in reporting practices of clinical laboratories throughout the
United States regarding ROH identified by SNP microarrays. This survey contained 15 closed-ended questions and 5 openended questions (Supplementary Appendix online). It was developed based on the authors' experience with SNP microarray reports and terminology relating to the field. The survey was reviewed and edited by the authors and was piloted for face validity by four colleagues.

\section{Survey measures}

The survey consisted of five parts. Part one queried respondents about demographic information including their gender, job title, duration of employment in a laboratory setting, length of time for which the laboratory has offered SNP microarray testing, and the name of the SNP microarray currently being run at the laboratory. Part two sought information listed on each laboratory's SNP microarray reports, including specifics about $\mathrm{ROH}$ and the laboratory's interpretations of $\mathrm{ROH}$. Part three asked participants to select their laboratory's definition of incest in terms of percentage of homozygosity, and indicate the number of occasions on which the laboratory has reported an array result that indicated the possibility of incest. Part four asked questions regarding the laboratory's duty to report findings of consanguinity or incest and any standard follow-up practices that they complied with. The follow-up practices were separated into (i) steps taken when consanguinity is found, and (ii) steps taken when incest is found. Part five included four open-ended questions to determine the laboratories' cutoff for reporting $\mathrm{ROH}$, their method of calculating the percentage of homozygosity, their method for differentiating between $\mathrm{ROH}$ and UPD, and their definition of ancestral ROH.

Each representative was contacted by telephone or e-mail and was offered the opportunity to complete the survey by telephone. If this was agreed to, a time and date were set to conduct the survey. Surveys conducted over the telephone were recorded, and open-ended questions were transcribed. In addition, potential responders were given the option of completing an online format of the survey, using http://www.surveymonkey.com (SurveyMonkey, Palo Alto, CA), an Internet website designed for the creation, distribution, and analysis of surveys through collection of responses. Those who elected not to complete the survey over the telephone were sent the website link. Nonresponders received follow-up emails 2 and 4 weeks after the initial contact. As a final reminder, laboratory representatives were again contacted by telephone to seek their participation.

\section{Data analysis}

The survey was conducted between September and December 2011. Telephone survey responses were entered into SurveyMonkey to ensure consistency in data analysis. The data were sorted and prepared for analysis using the SurveyMonkey software. Incomplete answers were excluded and removed from the final analysis. Frequencies were determined for each closed-ended question. Open-ended questions were postcoded according to common themes and frequencies for each theme were determined. 


\section{RESULTS}

\section{Respondent characteristics}

In total, 32 laboratories were invited to participate in the survey. Before completing the survey, six laboratories were excluded, five of these because they did not offer SNP microarrays, and one because it offered a SNP microarray testing for oncology samples only. Of the remaining 26 laboratories, seven declined to participate and one responded only to demography-related questions and was therefore excluded. A total of 18 laboratories completed the survey ( 5 by telephone and 13 online) for an overall response rate of $72 \%$. A total of $14(77.8 \%)$ laboratories reported using an Affymetrix platform and 4 (22.2\%) used an Illumina platform. Of the respondents, $6(33.3 \%)$ were genetic counselors, 11 (61.1\%) were laboratory directors, and 1 (5.6\%) was a clinical cytogeneticist/clinical geneticist. The respondents had been employed in a laboratory setting for the following time spans: 4 (22.2\%) for $0-2$ years; 2 (11.1\%) for 3-5 years; 4 (22.2\%) for 6-8 years; 1 (5.6\%) for 9-11 years; 1 (5.6\%) for $12-14$ years; and 6 (33.3\%) for $\geq 15$ years.

\section{Calculation of percentage of homozygosity}

The participants surveyed were asked to describe their laboratory's methods for calculation of percentage of homozygosity (Froh) from SNP microarray results. Of the 15 respondents to this question, $6(40 \%)$ reported that they added the total $\mathrm{Mb}$ of ROH identified and divided by the total $\mathrm{Mb}$ of DNA found in the entire genome; 8 (53.3\%) respondents stated that they divided the total $\mathrm{Mb}$ of $\mathrm{ROH}$ by the total $\mathrm{Mb}$ of DNA found in the autosomes only; and $1(6.7 \%)$ respondent stated that the laboratory did not calculate the percentage of homozygosity. A total of three respondents stated that it was the laboratory's practice to describe the method of calculation of Froh on their SNP microarray report. Our survey found that laboratories use varying size thresholds for reporting $\mathrm{ROH}$ and for calculating percentage of homozygosity. These varying thresholds are described in detail in a subsequent section in this paper.

\section{Definitions}

The respondents were asked to state their definitions of "ancestral ROH." The nine who responded provided different definitions: "the presence of $\mathrm{ROH}$ on a few chromosomes," a large number of (usually >50) independent stretches of homozygosity," " $1 \mathrm{Mb}$ blocks and higher" of $\mathrm{ROH}$, " $>3 \mathrm{Mb}$ blocks of $\mathrm{ROH}$," "ROH ranging in size from $0.5 \mathrm{Mb}$ to $10 \mathrm{Mb}$ but the majority range from 0.5 to $5-6 \mathrm{Mb}$," "a very low percentage of the genome being homozygous," based on "size and number of $\mathrm{ROH}^{\text {" found, "large }}$ blocks of homozygosity over multiple chromosomes," and many individuals have at least one $\mathrm{ROH} \geq 5 \mathrm{Mb}$." Of the nine respondents who did not supply a definition of "ancestral ROH," seven (38.9\%) stated that they do not define or report ancestral ROH, and two (11\%) were not sure how to define ancestral $\mathrm{ROH}$.

When asked to distinguish between $\mathrm{ROH}$ resulting from uniparental disomy versus consanguinity, 13 (72.2\%) respondents stated that if there is one large $\mathrm{ROH}$ on one chromosome it is caused by UPD, whereas multiple ROH on multiple chromosomes are caused by consanguinity; 2 (11\%) respondents indicated that they carry out additional testing to determine the cause of the $\mathrm{ROH} ; 1$ (5.6\%) respondent stated that the laboratory requests a family history and possible parental studies; and 2 (11\%) respondents either did not know or did not define a difference.

The respondent laboratories were asked how they define incest using percentage of homozygosity. Of the 18 respondents, $11(61.1 \%)$ used a threshold of $>20 \%$ as indicative of incest whereas $5(27.8 \%)$ used a threshold of $>12.5 \%$. The other two (11.1\%) respondents stated that they do not report incest in any situation. Of the $18(83.3 \%)$ respondents, 15 have at some time identified an SNP microarray suggestive of parental incest. Table 1 lists the number of times each laboratory reported observing this type of result, and the length of time they have been offering clinical SNP microarray testing.

\section{Variability in SNP microarray reports}

Table 2 contains the responses of the participants, including information on SNP microarray reports. Of note, $100 \%$ of the laboratories stated that in their reports they include (i) any microdeletions/microduplications found, (ii) syndrome(s) associated with the microduplications/microdeletions, (iii) the microarray nomenclature, (iv) the limitations of the testing, (v) the $\mathrm{ROH}$, and (vi) interpretation of findings. As shown in Table 3, the variability in reporting increases with respect to specific information about $\mathrm{ROH}$. Most of the respondents stated that their laboratories report the number, sizes, and locations of $\mathrm{ROH}$ as well as their recommendations based on the findings, whereas only

Table 1 Number of incest cases and years of running a SNP microarray

\begin{tabular}{lcl} 
Laboratory & $\begin{array}{c}\text { Cases of incest } \\
\text { reported }\end{array}$ & $\begin{array}{l}\text { Time offering } \\
\text { a SNP array }\end{array}$ \\
\hline 1 & $1-3$ & $2-3$ years \\
\hline 2 & 0 & $2-3$ years \\
\hline 3 & $10-12$ & $3-4$ years \\
\hline 4 & $1-3$ & $3-4$ years \\
\hline 5 & 0 & $>5$ years \\
\hline 6 & $1-3$ & $3-4$ years \\
\hline 7 & 0 & No response \\
\hline 8 & $1-3$ & No response \\
\hline 9 & $4-6$ & $2-3$ years \\
\hline 10 & $>15$ & $3-4$ years \\
\hline 11 & $1-3$ & $2-3$ years \\
\hline 12 & $1-3$ & $1-2$ years \\
\hline 13 & $1-3$ & $1-2$ years \\
\hline 14 & $4-6$ & $2-3$ years \\
\hline 15 & 0 & No response \\
\hline 16 & $10-12$ & $2-3$ years \\
\hline 17 & $>15$ & $1-2$ years \\
\hline 18 & $7-9$ & 2 years \\
\hline 59 & & \\
\hline
\end{tabular}

SNP, single-nucleotide polymorphism. 
Table 2 What information does your laboratory typically include in SNP microarray reports?

\begin{tabular}{|lcc|} 
Variable & $\boldsymbol{n}$ & $\%$ \\
\hline Interpretation of findings & 18 & 100 \\
\hline Microdeletions/microduplications found & 18 & 100 \\
\hline $\begin{array}{l}\text { Syndrome(s) associated with } \\
\text { microdeletions/microduplications found }\end{array}$ & 18 & 100 \\
\hline Microarray nomenclature & 18 & 100 \\
\hline ROH & 18 & 100 \\
\hline Limitations of testing & 18 & 100 \\
\hline Other appropriate testing & 17 & 94.4 \\
\hline Recommendation for referral for genetic counseling & 17 & 94.4 \\
\hline References & 17 & 94.4 \\
\hline Methodology & 17 & 94.4 \\
\hline Clinical implications & 16 & 88.9 \\
\hline $\begin{array}{l}\text { Suggestions for management techniques of an identified } \\
\text { disorder }\end{array}$ & 3 & 16.6 \\
\hline
\end{tabular}

$\mathrm{ROH}$, regions of homozygosity; SNP, single-nucleotide polymorphism.

Table 3 What does your laboratory typically include in SNP microarray reports about regions of homozygosity?

\begin{tabular}{lcc} 
Variable & $\boldsymbol{n}$ & $\%$ \\
\hline Size of $\mathrm{ROH}$ & 17 & 94.4 \\
Locations of $\mathrm{ROH}$ & 16 & 88.9 \\
Recommendations based on findings & 16 & 88.9 \\
Number of $\mathrm{ROH}$ & 15 & 83.3 \\
Percentage of the genome the $\mathrm{ROH}$ encompass & 10 & 55.5 \\
\hline
\end{tabular}

$\mathrm{ROH}$, regions of homozygosity.

$10 / 18$ (55.5\%) stated that they report percentage of homozygosity. Only 2 of the 18 stated that they report the size, number, and locations of ROH but only for cases of suspected UPD and not for consanguinity or incest. Of those that reported the percentage of homozygosity, one laboratory calculated and reported this information only for suspected cases of incest, and another only for cases of consanguinity or incest but not for UPD. A total of three respondents stated that they include a general statement about the risks associated with an $\mathrm{ROH}$ when a recessive disorder is known to map to the specific region where the $\mathrm{ROH}$ was found.

Each laboratory makes its own decision regarding the threshold value for reporting $\mathrm{ROH}$. Of the 18 respondents, 7 (41.1\%) set $\geq 10 \mathrm{Mb}$ of $\mathrm{ROH}$ as the threshold for reporting; 2 (11.8\%) used a threshold of $\geq 5 \mathrm{Mb}$, whereas another (5.9\%) used $\geq 8 \mathrm{Mb}$. Another 3 (17.6\%) respondents calculated the threshold on the basis of total percentage of the genome, with a threshold of either 2 or $3 \%$; the size of $\mathrm{ROH}$ in these calculations was not specified. In the case of 2 others (11.8\%), the threshold requirement was the presence of a single segment $\geq 10 \mathrm{Mb}$ or a total percentage of the genome $\geq 2 \%$ or $\geq 3 \%$ calculated using only $\mathrm{ROH} \geq 3 \mathrm{Mb}$. One laboratory $(5.9 \%)$ used a threshold of one $\mathrm{ROH}>10 \mathrm{Mb}$ or two or more $\mathrm{ROH}>5 \mathrm{Mb}$. One (5.9\%) laboratory set a threshold of 3-5\% of the genome to be homozygous using only $\mathrm{ROH}>3 \mathrm{Mb}$; once this threshold was met, smaller regions $(>1 \mathrm{Mb})$ were also included and added to the final calculation of percentage of homozygosity. One laboratory did not respond to this question. Although laboratories reported their cutoffs for $\mathrm{ROH}$, they were not asked to describe the rationale for adopting these cutoffs.

Table 4 summarizes the information that the laboratories stated as being included in their reports regarding interpretation of the findings of $\mathrm{ROH}$. All the laboratories stated that they report suspected UPD, $\sim 50 \%$ of them report when the parents are related by blood and there are findings of ancestral $\mathrm{ROH}$, and very few specify incest or the specific degree of relationship. Of 15 who responded to a specific question, 2 (13.3\%) stated that they report the suspected degree of relationship based on the $\mathrm{ROH}$ found; one of these laboratories reports the speculation only in cases of suspected incest, whereas the other reports the speculation in suspected cases of parental consanguinity as well as of parental incest.

\section{A laboratory's duty to report}

All 18 survey respondents were of the opinion that it was their duty to notify the ordering physician of results suggestive of consanguinity or incest. The respondents were offered an opportunity to elaborate on this topic, and 13 of them went on to explain their reasoning. These respondents explained their reasoning as follows: (i) 3 (23\%) respondents stated that this duty applied only to cases of incest, not to those of consanguinity; (ii) $3(23.0 \%)$ respondents felt that their duty to report arose from the "legal and ethical issues," such as the duty to report child abuse; (iii) 2 (15.4\%) respondents cited medical necessity as being the reason for reporting the findings, given that the test result could influence a diagnosis or future family planning; (iv) $2(15.4 \%)$ respondents stated that they notify the ordering physician of every abnormal result, whether it shows a deletion or multiple ROH; and (v) 3 (23.0\%) respondents stated that they were generally informed of parental relationship, if any, ahead of the testing, but felt it is their duty to inform the ordering physician if new information was found.

A total of 10 (55.6\%) respondents stated that the action taken by them differed depending on whether a test result revealed consanguinity or not. Specifically, these 10 respondents stated that they always contacted the ordering health-care provider when consanguinity was revealed. Of these, $4(40 \%)$ had the practice of recommending that the ordering physician should take additional steps such as performing clinical testing for a recessive disorder suggested by the phenotype observed and the $\mathrm{ROH}$ found. None of the laboratories directly contacted the legal authorities, social work teams, or an ethics board. A total of $14(77.8 \%)$ respondents stated that the actions taken by them differed depending on whether a result suggested an incestuous relationship or not. All 14 stated that they have contacted the ordering health-care provider in cases of suspected incest. Of these, $3(21.4 \%)$ had the practice of recommending that the ordering physician take additional steps, $2(14.3 \%)$ had the practice of contacting an ethics board, and 
Table 4 Which of the following interpretations of the findings of $\mathrm{ROH}$ does your laboratory report typically include?

\begin{tabular}{lcc} 
Variable & $\boldsymbol{n = 1 8}$ & $\mathbf{\%}$ \\
\hline Uniparental disomy & 18 & 100 \\
\hline Parents related by blood & 10 & 55.6 \\
\hline Ancestral ROH & 8 & 44.4 \\
\hline Degree of relationship suspected & $2^{\mathrm{a}}$ & 13.3 \\
\hline Incest & 2 & 11.1 \\
\hline
\end{tabular}

$\mathrm{ROH}$, region of homozygosity.

aData available from only 15 laboratories.

$1(7.1 \%)$ had the practice of contacting social workers. None of the laboratories had contacted the legal authorities.

\section{DISCUSSION}

SNP microarrays can detect ROH that can imply UPD or parental consanguinity/incest. Most of the laboratories who responded to our survey stated that they suspected UPD when SNP microarray detected an $\mathrm{ROH}$ on a single chromosome, and considered the possibility of a parental blood relationship when multiple $\mathrm{ROH}$ were identified on multiple chromosomes. All the $\mathrm{ROH}$ found can be summed to calculate the percentage of homozygosity, which can then be compared to known inbreeding coefficients to estimate the degree of parental relatedness. ${ }^{7,918}$ The reporting of $\mathrm{ROH}$ in the context of parental relatedness varied among the laboratories, but all stated that they reported $\mathrm{ROH}$ suggesting UPD. There were variations in the methods of determining the various parameters involved: (i) different cutoff standards for reportable size were applied, both for UPD and for $\mathrm{ROH}$, (ii) different cutoff standards for size of $\mathrm{ROH}$ used in calculating percentage of homozygosity, (iii) the use of either the whole genome or the autosome as the basis for calculating percentage of homozygosity. There were also differences in the follow-up practices when $\mathrm{ROH}$ findings suggested parental relatedness.

Papenhausen et al. ${ }^{6}$ recently studied a large number of cases of suspected UPD. They suggested that a reasonable screening threshold to determine UPD would be an interstitial ROH $>20 \mathrm{Mb}$ or a telomeric $\mathrm{ROH}>10 \mathrm{Mb}$ (although a telomeric $\mathrm{ROH}$ has a higher index for suspicion and therefore a lower threshold may be warranted). They excluded cases with an $\mathrm{ROH}>10 \mathrm{Mb}$ on a second chromosome, because that indicates identity by descent. Papenhausen's study provides a strong starting point for the delineation of cutoffs for reporting $\mathrm{ROH}$, both in terms of UPD and in terms of parental relatedness. Even when standardized cutoffs are used for calculations, it would be prudent for the laboratory to communicate closely with the ordering health-care provider about clinical indications and possible differential diagnoses. This is because even small $\mathrm{ROH}$, below a reportable threshold, may harbor a candidate gene. Furthermore, microarray studies can only suggest the presence of UPD or autosomal recessive disease and need to be followed up with methylation or trio genotype analysis to confirm UPD, or with sequence analysis to confirm a recessive mutation.
Variations in SNP microarray reporting may be attributable to a lack of established guidelines and/or differing professional opinions regarding reportable results (see Tables 2-4). Current technology enables the identification of possible parental consanguinity or incest on the basis of SNP microarray results. However, 8 of the 18 laboratories (44.4\%) surveyed chose not to report the possibility of parental consanguinity and 16 (88.9\%) did not include the possibility of parental incest in their reports even when the findings suggested it. There are no guidelines about whether such incidental findings should be included in a laboratory report. There are several reasons why laboratories may choose not to report suspected parental relatedness. These include concerns that the percentage of homozygosity may be an overestimate, complicated by multiple generations of inbreeding or ancestral $\mathrm{ROH}$. There may also be concerns about methods for calculation of percentage $\mathrm{ROH}$ and classification of the degree of relatedness, and/or inaccurate family histories. It is also possible that laboratories consider findings of consanguinity or incest to be incidental findings, given that this was not the purpose of the SNP microarray testing.

Although all the respondents in this survey said that it was their duty to notify the ordering physician when the results were suggestive of consanguinity or incest, they were unclear about the proper steps to take. Some laboratories rationalized their decision to report $\mathrm{ROH}$ as being based on the need for follow-up medical management or testing if a recessive condition is identified; others were of the opinion that "legal and ethical issues" were involved in the decision regarding whether to report possible consanguinity and incest. For these reasons, many respondents stated that they contact the ordering physician directly to discuss the results even if they do not include the information in their reports. Neither results suggesting consanguinity nor results indicating incest triggered steps by the laboratories to contact legal authorities. In addition, only one laboratory had the practice of contacting a social worker team when incest was suspected. A reluctance to contact social workers or legal authorities could be because of difficulty in accessing a social work team, uncertainty regarding family history, uncertainty regarding additional demographic/clinical information, a lack of precedence regarding the use of SNP microarrays as proof in a legal setting, and the belief that it is the ordering physician's job to intervene.

Microarray results relating to homozygosity may also lead to legal dilemmas for laboratories and ordering physicians, potentially having an impact on clinical practice. In the clinic, physicians must balance their duty to report abuse with the privileged physician-patient relationship that is protected by the Health Insurance Portability and Accountability Act. For example, Ohio Revised Code 2151.421 states that any individual who is a physician or health care professional is required to report to the appropriate county child services agency or police authority "in the county in which the child resides or in which the abuse or neglect is occurring or has occurred" any "facts that would cause a reasonable person in a similar position to suspect, that a child under 18 years 
of age or a mentally retarded, developmentally disabled, or physically impaired child under 21 years of age has suffered or faces a threat of suffering any physical or mental wound, injury, disability, or condition of a nature that reasonably indicates abuse or neglect of the child ..."19 Ohio Revised Code 5123.61 extends this same requirement for individuals who are of any age with mental retardation or developmental disability. ${ }^{20}$ However, these laws do not require reporting when there is evidence of an adult son or daughter with full mental capacity engaging in an incestuous relationship with the mother or father; in fact, such a report would be a violation of the Health Insurance Portability and Accountability Act.

Ohio laws require any health care professional, including laboratory personnel, to report suspected child abuse. However, in most circumstances, laboratory personnel do not have access to all the information (family history, patient's mental status, age of a parent at pregnancy/conception, and/ or psychosocial status) that might lead one to a suspicion of child abuse. Rather, they have only one piece of the puzzle, the microarray results. We therefore suggest that either the physician alone, or a physician/laboratory team should assemble all the relevant information and make a decision about whether to contact the legal authorities.

There are several limitations to this study. The respondents identified themselves as being familiar with the SNP microarray at their respective laboratories, reported a range of experience levels, and recalled past results as well as considering hypothetical situations, none of which were possible for the researchers to validate. In addition, the number of respondent laboratories performing SNP microarrays was small.

With increasing numbers of laboratories offering SNP microarray testing, it is essential to develop guidelines for reporting incidental findings such as suspected consanguinity and incest. Tsuchiya et al. ${ }^{21}$ described other sources of variability with regards to the content of clinical reports; they suggested that there should be more specific guidelines for reporting copynumber changes. Our study also demonstrates that there is variability in the reporting practices of clinical laboratories with respect to $\mathrm{ROH}$ as identified by SNP microarrays, and in the actions taken by them for follow-up of such results. This study highlights the need for laboratory guidelines relating to the incidental detection of $\mathrm{ROH}$ so as to help laboratories to address legal and ethical dilemmas that may arise. Such guidelines will ensure consistency in reporting and follow-up and enable laboratories to take the recommended steps whenever genetic testing suggests parental consanguinity or incest. The concerns identified in this study will be amplified as the capability to detect parental consanguinity or incest extends to other genetic tests, such as whole-exome/whole-genome sequencing. It is imperative that the genetics community develop guidelines to address these concerns, both in the laboratory and in the clinic.

\section{SUPPLEMENTARY MATERIAL}

Supplementary material is linked to the online version of the paper at http://www.nature.com/gim

\section{ACKNOWLEDGMENTS}

The authors thank Bob Carpenter of Cincinnati Children's Hospital Medical Center for providing assistance with interpreting the Ohio Revised Code.

\section{DISCLOSURE}

The authors declare no conflict of interest.

\section{REFERENCES}

1. Li MM, Andersson HC. Clinical application of microarray-based molecular cytogenetics: an emerging new era of genomic medicine. J Pediatr 2009;155:311-317

2. Manning M, Hudgins L. Array-based technology and recommendations for utilization in medical genetics practice for detection of chromosomal abnormalities. Genet Med 2010;12:742-745.

3. Schaaf CP, Scott DA, Wiszniewska J, Beaudet AL. Identification of incestuous parental relationships by SNP-based DNA microarrays. Lancet 2011;377:555-556.

4. Miller DT, Adam MP, Aradhya S,et al. Consensus statement: chromosomal microarray is a first-tier clinical diagnostic test for individuals with developmental disabilities or congenital anomalies. Am J Hum Genet 2010;86:749-764.

5. Conlin LK, Thiel BD, Bonnemann CG,et al. Mechanisms of mosaicism, chimerism and uniparental disomy identified by single nucleotide polymorphism array analysis. Hum Mol Genet 2010;19:1263-1275.

6. Papenhausen P, Schwartz S, Risheg $H$,et al. UPD detection using homozygosity profiling with a SNP genotyping microarray. Am J Med Genet $A$ 2011;155A:757-768.

7. Kearney HM, Kearney JB, Conlin LK. Diagnostic implications of excessive homozygosity detected by SNP-based microarrays: consanguinity, uniparental disomy, and recessive single-gene mutations. Clin Lab Med 2011;31:595-613, ix

8. Kirin M, McQuillan R, Franklin CS, Campbell H, McKeigue PM, Wilson JF. Genomic runs of homozygosity record population history and consanguinity. PLOS ONE 2010;5:e13996

9. McQuillan R, Leutenegger AL, Abdel-Rahman R,et al. Runs of homozygosity in European populations. Am J Hum Genet 2008;83:359-372.

10. Bittles A, Black M. Consanguinity, human evolution, and complex diseases. Proceedings of the National Academy of Sciences (PNAS) 2010;107: 1781-1786.

11. Hamamy H. Consanguineous marriages: Preconception consultation in primary health care settings. J Community Genet 2011; e-pub ahead of print 22 November 2011.

12. Hamamy H, Antonarakis SE, Cavalli-Sforza LL,et al. Consanguineous marriages, pearls and perils: Geneva International Consanguinity Workshop Report. Genet Med 2011;13:841-847.

13. Bennett RL, Motulsky AG, Bittles A,et al. Genetic counseling and screening of consanguineous couples and their offspring: recommendations of the National Society of Genetic Counselors. J Genet Counsel 2002;11:97-119.

14. Paul DB, Spencer HG. "It's ok, we're not cousins by blood": the cousin marriage controversy in historical perspective. PLOS Bio/ 2008;6:2627-2630.

15. Jancar J, Johnston SJ. Incest and mental handicap. J Ment Defic Res 1990; 34 (Pt 6):483-490.

16. Alkuraya FS. Homozygosity mapping: one more tool in the clinical geneticist's toolbox. Genet Med 2010;12:236-239.

17. Bruno DL, Ganesamoorthy D, Schoumans J,et al. Detection of cryptic pathogenic copy number variations and constitutional loss of heterozygosity using high resolution SNP microarray analysis in 117 patients referred for cytogenetic analysis and impact on clinical practice. J Med Genet 2009;46:123-131.

18. Franklin IR. The distribution of the proportion of the genome which is homozygous by descent in inbred individuals. Theor Popul Biol 1977;11:60-80.

19. Reporting child abuse or neglect, 2151.421 Title 21. Courts-Probate-Juvenile (2004).

20. Reporting abuse, neglect, and other major unusual incidents, 5123.61 Title 51 Public Welfare (2004).

21 Tsuchiya KD, Shaffer LG, Aradhya S, et al. Variability in interpreting and reporting copy number changes detected by array-based technology in clinical laboratories. Genet Med 2009;11:866-873. 